\title{
Updating Canada's National Forest Inventory with multiple imputations of missing contemporary data
}

\author{
by Steen Magnussen ${ }^{1 *}$, Graham Stinson ${ }^{1}$ and Paul Boudewyn ${ }^{1}$
}

\begin{abstract}
Canada's National Forest Inventory (NFI) is facing an issue of spatial imbalance in photo interpreted data from 400 ha photo-plots available for estimation of state and change. Multiple imputations (MI) of missing data is therefore considered as a means to mitigate a potential bias arising from spatial imbalance, and-to a lesser degree- improve the precision relative to what can be achieved with the subset of plots having current data. In this study we explored MI with data from three study sites located in the provinces of Quebec, Ontario, and Saskatchewan. Specifically, we looked at state at time $T_{2}$ and change between $T_{1}$ and $T_{2}$ in cover-type area proportions and in per unit area stem volume. At each location we found significant $T_{1}$ differences in these attributes between plots with and without $T_{2}$ data. A MI procedure with 20 replications of stochastic model-based imputations of missing data was therefore effective as a way to mitigate a bias that would arise if $T_{2}$ inference was based exclusively on plots with $T_{2}$ data. Possible differences between the $T_{2}$ and $T_{1}$ photointerpretation, paired with no efficient stratification of disturbed and undisturbed plots, largely eliminated expected gains in precision from the MI boosting of the effective $T_{2}$ sample size. Despite recognized limitations, we recommend MI as an effective tool to counteract an emerging spatial imbalance in the NFI.
\end{abstract}

Key words: forest cover-types, area proportions, stem volume, disturbance rates, ratio estimators.

\section{RÉSUMÉ}

Linventaire forestier national du Canada (NFI) est confronté à une problématique de déséquilibre dans les données de placettes photographiques de 400 ha disponibles pour évaluer létat de la forêt et son changement. On envisage donc d'utiliser l'imputation multiple (MI) des données manquantes afin d’amoindrir le biais occasionné par le déséquilibre spatial et, dans une moindre mesure, améliorer la précision par rapport à ce qu'il est possible d’atteindre avec le sous-ensemble de placettes pour lesquelles nous disposons de données à jour. Dans cette étude, nous avons exploré les possibilités de MI avec les données provenant de trois sites détude situés dans les provinces de Québec, de l'Ontario et de la Saskatchewan. De façon plus particulière, nous nous sommes intéressés à létat à temps $T_{2}$ et au changement survenu entre $T_{1}$ et $T_{2}$ dans les proportions des surfaces par type de couvert et le volume par tige par unité de surface. À chaque endroit nous avons observé des différences significatives pour ces paramètres à $T_{1}$ selon qu’on utilisait ou non les données de $T_{2}$. Une procédure MI avec 20 répétitions d'imputations des données manquantes basées sur un modèle stochastique seest avérée efficace pour atténuer le biais qui résulterait si l'inférence à $T_{2}$ reposait uniquement sur les placettes disposant des données à $T_{2}$. Toutefois, les différences dans la technique de photo-interprétation à $T_{1}$ et à $T_{2}$ combinées à l'absence de stratification des placettes perturbées et intactes a masqué la majeure partie du gain en précision quon aurait pu espérer avec une bonification de la taille des échantillons à $T_{2}$. Malgré ces limitations, nous recommandons l'utilisation de MI pour amoindrir les effets d'un déséquilibre anticipé dans l'inventaire forestier national.

Mots-clés: types de couverts forestiers, proportion des surfaces, volume par tige, taux de perturbation, estimateurs par quotients.

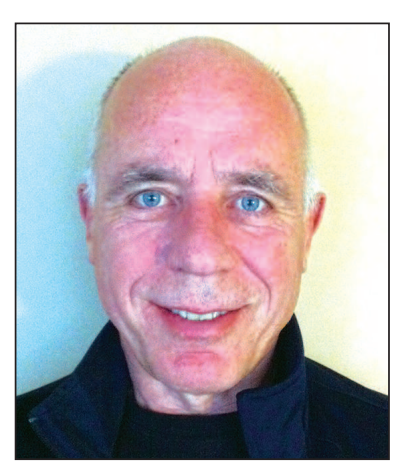

Steen Magnussen

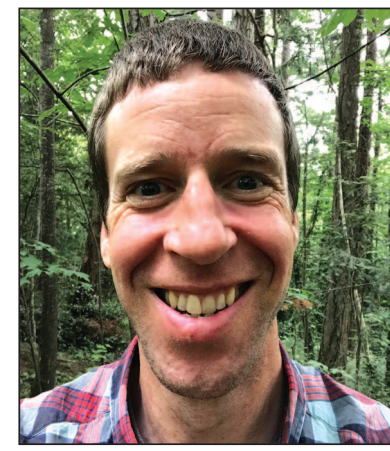

Graham Stinson

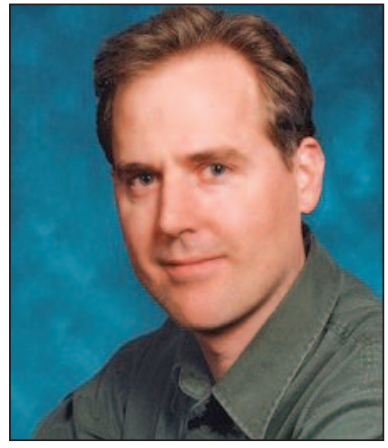

Paul Boudewyn

${ }^{1}$ Canadian Forest Service, 506 West Burnside Road, Victoria BC V8Z 1M5, Canada. ${ }^{\star}$ Correspondence email: steen.magnussen@canada.ca 


\section{Introduction}

National and regional forest inventories commonly employ a regular spatial network of permanent sample plots to furnish estimates of state and change between successive measurements (Pelz and Cunia 1985, Reams and Van Deusen 1999, Tomppo 2006, Haywood et al. 2016). A small proportion of the sample plots may not deliver data when access is denied by the forest owner, or when plot measurements are deemed too dangerous to carry out (McRoberts 2003, Patterson et al. 2012, Corona et al. 2014). Unplanned events and lack of funding may also create data imbalance. A point may be reached when estimates derived from available data may be lacking in both accuracy and precision. Bias may be introduced when data are not missing at random (Little and Rubin 1987, Glynn et al. 1993, Domke et al. 2014). This situation can arise when the probability of missing plot data from a specific plot is related in some fashion to the variable of interest (e.g., per unit area stem volume). Evidently, precision suffers from any reduction in sample size due to missing data.

Forest inventories have a long history of successfully exploring and implementing mitigating options under the generic labels of modeling, imputation, and reweighting (Dixon and Howitt 1979, Matis et al. 1984, Cunia and Kyaw 1985, Kangas 1991, Bokalo et al. 1996, Van Deusen 1996, Crookston and Finley 2008). Canada's National Forest Inventory (NFI) (Gillis et al. 2005, Stinson et al. 2016) is facing an issue of data imbalance. Options to address the imbalance in photo-interpreted data are needed. The core NFI's systematic sampling framework was established during the period 2000-2006 $\left(T_{1}\right)$ with $2 \times 2 \mathrm{~km}$ photo-interpreted plots on a nominal $20 \times 20 \mathrm{~km}$ grid. The current measurement cycle (2008-2017) is designed to provide time $T_{2}$ estimates of state and time $T_{2}-T_{1}$ estimates of change. The completion of this cycle will present the first opportunity to produce estimates of change. For reasons related to logistics and funding, only a subset of sample units will have been updated to their state at $T_{2}$. It appears that units with $T_{2}$ information will not be spatially balanced which raises the possibility of bias.

This study explores multiple imputations (MI) (Rubin 1987, Van Deusen 1997, McRoberts 2003, Carpenter and Kenward 2013) as an option to mitigate the possible bias due to a spatial imbalance in the NFI data. MI is conceptually simple (Carpenter and Kenward 2013). A missing datum is replaced by the sum of a model-dependent expectation plus a random (stochastic) error. A data set with imputed values is then analysed as if it was complete. Due to the random component of an imputation, repeating the imputations will generate different results. As well, all estimates of uncertainty will be downward biased as the uncertainty in an imputation is ignored. To account for the uncertainty in an imputation, the process of imputation is repeated $M$ times and the final mean (total) is estimated as the mean across the $M$ imputations, and the variance of this mean is the average estimate of the variance within an imputation plus the variance among the $M$ estimates of a mean (total).

Our objectives were to: $i$ ) determine if MI could be used to produce reliable estimates of forest state at $T_{2}$ and change between $T_{1}$ and $T_{2}$ using incomplete $T_{2}$ survey data; and ii) more broadly illustrate $\mathrm{MI}$ with data from very large sample units containing multiple cover-types.

\section{Material and Methods}

Estimation objectives and sample data

Design-based estimators of the mean of multiple inventory variables $\mathrm{Y}$ at time $T_{2}$ and the change in the mean of these variables since time $T_{1}$ is required for a population of interest. Estimates of sampling variance are also required. Specifically we focus on the state and change in five cover-type area-proportions and per unit area stem volume. The covertypes are NA (non-forest land), NT (non-treed forest land), TB (treed, broadleaves), TM (treed, mixed-wood), and TC (treed, conifers). The sum of cover-type proportions in NT, TB, TM, and TC is labelled as FO for the proportion of total forest land cover (MacDicken 2015). The area of a sample unit is the sum of the areas in the five cover-types (NA, NT, $\mathrm{TB}, \mathrm{TM}$, and TC).

Photo-interpreted data for these estimators come from $n$ permanent 400 ha sample units located on a $20 \times 20 \mathrm{~km}$ grid (Gillis et al. 2005). There is a full complement of $n$ sample units with $T_{1}$ data but $T_{2}$ data is limited to a smaller subset of $n_{\text {obs }}<n$ units. The number of sample units without $T_{2}$ information is $n-n_{\mathrm{obs}}$. Note that the timing of data collection in Canada's NFI is largely determined by Provincial and Territorial jurisdictions (Stinson et al. 2016). Data in support of an estimate of state at $T_{t}$ will have been collected during a multiyear period. An estimate of change between nominal years $T_{1}$ and $T_{2}$ will therefore cover change during both shorter and longer periods.

If the missing $T_{2}$ data were missing completely at random with respect to the $T_{1}$ data we could obtain unbiased estimates of state at $T_{2}$ and change since $T_{1}$ and MI would only serve to increase precision. If there are differences between plots having $T_{2}$ data and those where $T_{2}$ data are missing, then MI could prove helpful for reducing bias and improving precision. To determine if $T_{1}$ values in plots with and without $T_{2}$ information were exchangeable, we tested for equality in area proportions in units with and without $T_{2}$ data (Miller 1981). We found significant differences at each study site. Tests ( $t$-test) of equal per unit area stem volume also indicated a significant difference in at least one of the cover types TB, TM, and TC. Permutation tests (Good 1993) of complete spatial randomness in the assignment of sample units to either category (with or without $T_{2}$ data) suggested a non-random spatial pattern in the units with missing $T_{2}$ information.

\section{Data}

We have three study locations for the demonstration and assessment of MI in the context of photo-interpreted NFI data (Fig. 1-3) from $2 \times 2 \mathrm{~km}$ sampling units (photo-plots). Two regions, labelled as QC6 and ON6, are located in the terrestrial ecozone 6 (Boreal shield) of Québec and Ontario, respectively. The third (SK9) is located in terrestrial ecozone 9 (Boreal plains) of Saskatchewan. Data from a photo-plot is provided by expert photo-interpreters who delineate forest stands (forest cover polygons) and measure or interpret stand-level forest attributes following the NFI data dictionary (https://nfi.nfis.org/en/photo_plot). Lookup tables, yield tables, and models are used to calculate volumes for each forest stand layer. For each $2 \times 2 \mathrm{~km}$ unit we use $T_{1}$ and $T_{2}$ data on the area in each of the cover-types NA, NT, TB, TC, TM, and $\mathrm{FO}(=\mathrm{NT}+\mathrm{TB}+\mathrm{TC}+\mathrm{TM})$ and the total stem volume associated with these areas. 


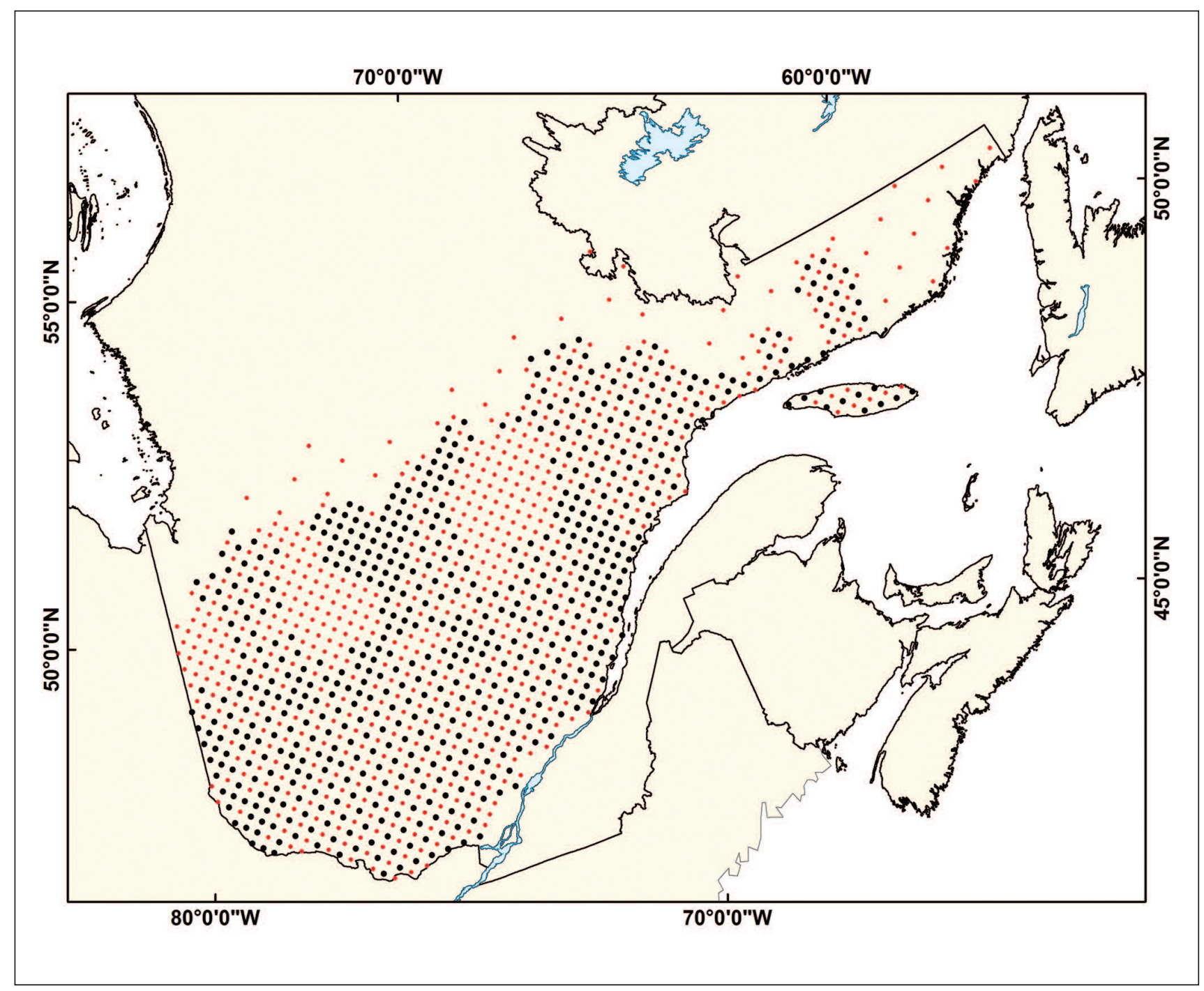

Fig. 1. Location map of NFI units in study region QC6 in Québec. Black: locations have $T_{1}$ and $T_{2}$ data. Red: locations have $T_{1}$ data only.

Currently the NFI contains a large number of units with $T_{1}$ information sourced from the Earth Observation of Sustainable Development land-cover mapping project (Wulder and Nelson 2003, Wulder et al. 2008). These plots were excluded from our analyses.

QC6: All $2 \times 2 \mathrm{~km}$ plots are located between longitudes $62^{\circ}$ and $80^{\circ} \mathrm{W}$ and between latitudes $45^{\circ}$ and $52^{\circ} \mathrm{N}$ (Fig. 1). The total sample size in the QC6 location is 1272 of which 662 (52\%) have $T_{1}$ and $T_{2}$ and $610(48 \%)$ only have $T_{1}$ data. The median $T_{1}$ year is 1998 for the plots without $T_{2}$ data (interquartile range (IQR): 1995-2001). For plots with both $T_{1}$ and $T_{2}$ data, the median $T_{1}$ year is 1996 (IQR = 1991-1998). The median $T_{2}$ year was 2011 (IQR: 2008-2012). The forests are boreal with a predominance of black spruce (Picea mariana), paper birch (Betula papyrifera), and balsam fir (Abies balsamea). Other important species are sugar maple and trembling aspen. The area contains non-boreal forests in the southernmost sections.

ON6: All plots are located between longitudes $76^{\circ}$ and $95^{\circ}$
$\mathrm{W}$ and between latitudes $44^{\circ}$ and $52^{\circ} \mathrm{N}$ (Fig. 2). The total sample size in the ON6 location is 1210 of which 459 (38\%) have $T_{1}$ and $T_{2}$ and 751 (62\%) only have $T_{1}$ data. The median $T_{1}$ year for plots with no $T_{2}$ data is 1997 (IQR: 1995-2005), and 1996 (IQR: 1995-2004) for the plots with both $T_{1}$ and $T_{2}$ data. The median $T_{2}$ year is 2008 (IQR: 2008-2010). The forests are boreal with a predominance of black spruce, trembling aspen (Populous tremuloides), and jack pine (Pinus banksiana). Other important species are paper birch and sugar maple (Acer saccharum). The area transitions to nonboreal forests in the south.

SK9: All plots are located between longitudes $102^{\circ}$ and $110^{\circ} \mathrm{W}$ and between latitudes $52^{\circ}$ and $58^{\circ} \mathrm{N}$ (Fig. 3). The total sample size in the SK9 location is 380 of which $242(64 \%)$ have $T_{1}$ and $T_{2}$ and $138(36 \%)$ have $T_{1}$ data. The median $T_{1}$ year is 2003 (IQR: 2001-2006), while the median $T_{2}$ year is 2010 (IQR: 2009-2012). The forests are boreal with a predominance of black spruce, jack pine and trembling aspen. Other minor species present are tamarack and white spruce. 


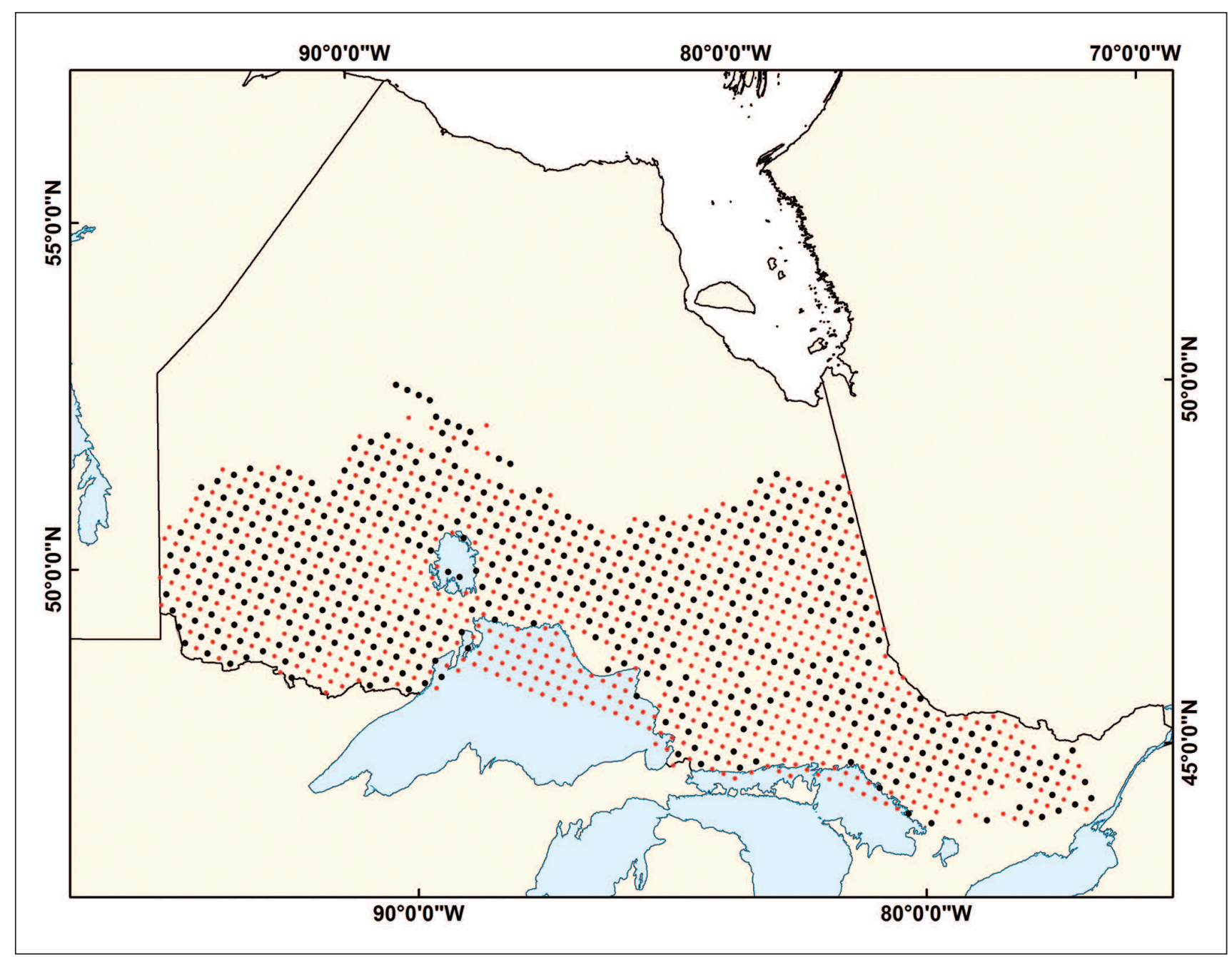

Fig. 2. Location map of NFI units in study region ONG in Ontario. Black: locations have $T_{1}$ and $T_{2}$ data. Red: locations have $T_{1}$ data only.

\section{Multiple imputations}

The desired estimators for $T_{2}$ and the period $T_{2}-T_{1}$ are the means, $\bar{y}_{1}$ and $\bar{y}_{2}$ the variances $\hat{V}\left(\bar{y}_{1}\right)$ and $\hat{V}\left(\bar{y}_{1}\right)$ and the covariance $\operatorname{COV}\left(\bar{y}_{1}, \bar{y}_{2}\right)$. They can all be derived from the available data from the $n_{\text {obs }}$ sample units with $T_{1}$ and $T_{2}$ data. But for reasons outlined, it was decided to explore MI (Carpenter and Kenward 2013) for estimation with the full complement of $n$ sample units. MI works by replacing a missing $T_{2}$ datum in the $n_{o b s}+k t h$ sample unit by $\tilde{y}_{2, n_{o b s+k}}, k=n_{o b s+1}, \ldots, n$ viz. the sum of a model-based expectation and a stochastic error. The imputations are thus model-based, with models derived from the sample units with both $T_{1}$ and $T_{2}$ data. To reduce the stochastic influence on the estimators, an average is taken over $M$ replications of the imputation and estimation steps (Table 1). From the $n_{\text {obs }}$ units with actual $T_{1}$ and $T_{2}$ data, and imputations of $T_{2}$ data in $n-n_{\mathrm{obs}}-1$ units, all required design-consistent estimators can be obtained using the estimators applied to a set of $n$ complete observations. With stochastic imputations, the mean and variance of $n-n_{\mathrm{obs}}-1$ imputed values varies among replications of the imputation process (Van Deusen 1997, McRoberts 2001). This is illustrated in Table 1 where we have $M$ replications of the imputation process and therefore $M$ estimates of the mean, and vari- ance. We also obtain $M$ estimates of covariance and correlation between the $T_{1}$ and $T_{2}$ means which we need for estimating the variance of an estimated change. In our MI scheme the stochastic errors are exclusively generated from an estimate of the 'lack-of-fit' residuals in the underlying model(s). In other words, we ignore that estimates from a photo-interpretation are subject to errors. The impact of these errors comes from errors in $T_{1}$ estimates as they attenuate the estimates of slope in a regression model (Fuller 1987).

The final MI estimators of mean and variance at time $T_{2}$ are given in [1] (Little and Rubin 1987, Rubin 1987, Carpenter and Kenward 2013).

$$
\begin{aligned}
& \text { [1] } \bar{y}_{2}^{M I}=M^{-1} \sum_{j=1}^{M} \overline{\tilde{y}}_{2}^{(j)}, \tilde{V}_{M I}\left(\bar{y}_{2}^{M I}\right)=M^{-1} \sum_{j=1}^{M} \hat{V}\left(\overline{\tilde{y}}_{2}^{(j)}\right) \\
& \quad+\frac{\left(1+M^{-1}\right)}{(M-1)} \sum_{j=1}^{M}\left(\overline{\tilde{y}}_{2}^{(j)}-\bar{y}_{2}^{M I}\right)^{2}
\end{aligned}
$$

The MI mean is the mean across the $M$ imputation, and the variance is the mean of the estimated variances plus the variance of the estimated means.

The number $M$ of replications was determined by considering the Monte Carlo error (Koehler et al. 2009) and the fraction of missing information (FMI) (Carpenter and Ken- 


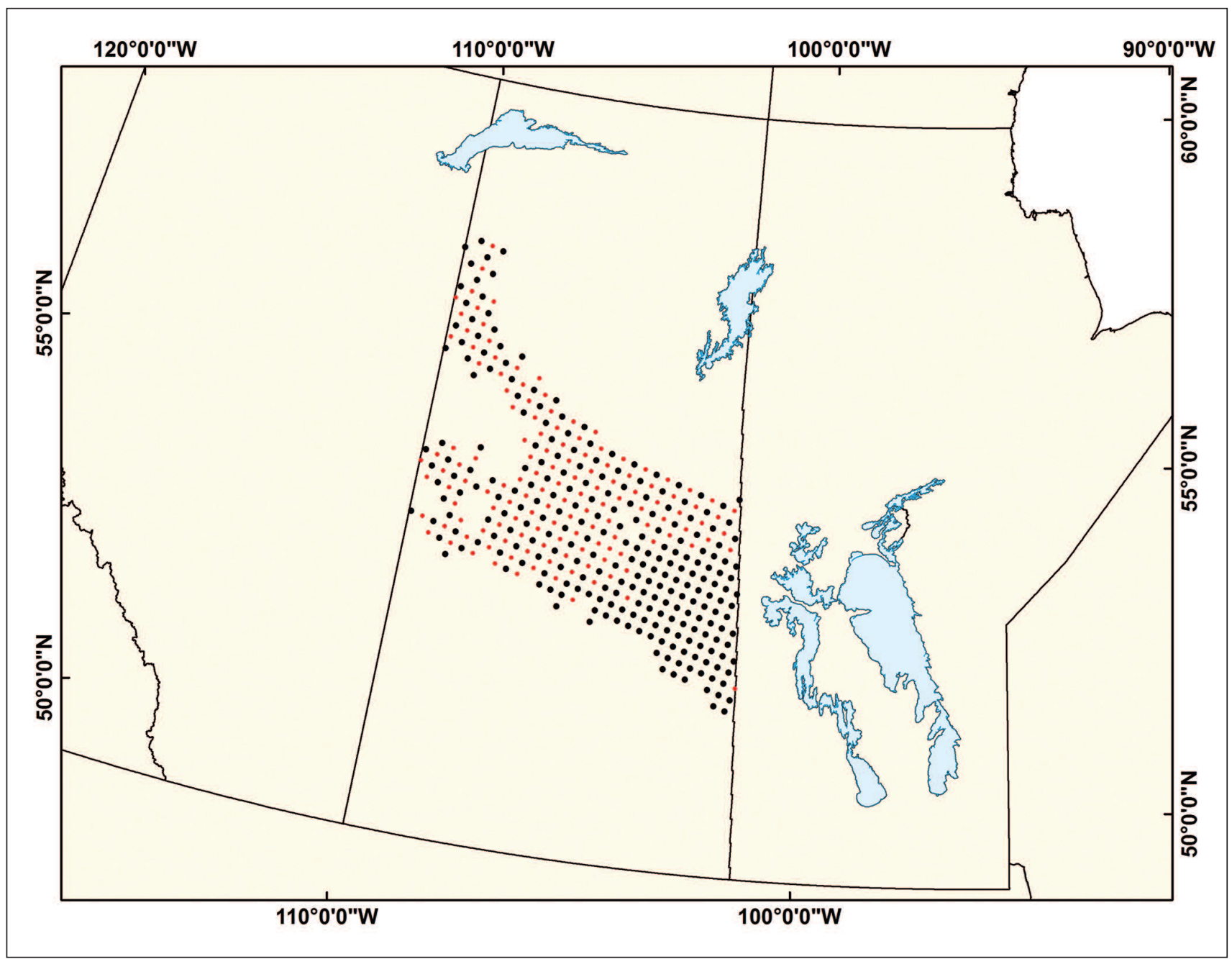

Fig. 3. Location map of NFI units in study region SK9 in Saskatchewan. Black: locations have $T_{1}$ and $T_{2}$ data. Red: locations have $T_{1}$ data only.

ward 2013). We decided on $M=20$ because the Monte Carlo error was then an order of magnitude smaller than the estimate of sampling error, and estimates of FMI had stabilized to within $3 \%$.

Our MI procedures rely on the assumption that the models for the imputations apply without modification to units without $T_{2}$ data so that we can regard the missing data (values) as missing at random given the information available at $T_{1}$ (Carpenter and Kenward 2013). We did not have means to test this assumption, but the large degree of spatial overlap between the units with and without $T_{2}$ data (cf. Fig. 1-3) lends support to the use of models derived from units with $T_{2}$ data.

\section{$\mathrm{Ml}$ estimation of state and change in area proportions}

Estimation of area proportions at $T_{2}$ followed the schemata in Table 1. In each of the $M$ replications of a stochastic imputation, a missing $T_{2}$ value of an area proportion was imputed as $\tilde{y}_{2, j}^{(M)}=\hat{y}_{2, j}^{(M)}+\tilde{e}_{2, j}^{(M)}, j=n_{\text {obs }}+1, \ldots, n$ where $\hat{y}_{2, j}^{(M)}$ is a model-

based replication-specific prediction from a truncated regression (Greene 2012) of the expected area proportion at time $T_{2}$ given the area proportion at time $T_{1}$ and $\tilde{e}_{2, j}^{(M)}$ is a replication- specific stochastic error. No other $T_{1}$ variable qualified as a significant predictor. Model-based replication-specific predictions of the expected proportion (i.e. $\bar{y}_{2 j}^{(M)}$ ) were generated via: 1) a random draw $\left(\hat{\sigma}_{e}^{2}\right)$ from the assumed chi-squared distribution of the residual variance in the regression of $T_{2}$ area proportions on $T_{1}$ area proportions; and 2) a random draw of regression coefficients (intercept and slope) from the assumed distribution of the regression coefficients given $\hat{\sigma}_{e}^{2}$. Finally $\tilde{e}_{2, j}^{(M)}$ was obtained via a random draw from a normal distribution with mean zero and a variance $\hat{\sigma}_{e}^{2}$ (Carpenter and Kenward 2013). While we have ignored errors in photo-interpreted estimates, it should be emphasized that our imputations are consistent as predictions of the data (with interpretation errors) that one can expect given the established relationship between $T_{1}$ and $T_{2}$ data and the assumption of temporally constancy in the photo-interpretation (Carroll et al. 1995).

As implemented in the statistical software STATA ${ }^{\circ}$ (StataCorp 2016), all imputed values $\bar{y}_{2, j}^{(M)}$ were restricted to the allowed interval from 0 to 1 for a proportion. The truncated regression failed to converge to a solution for NA in ON6 and SK9 and for NT in ON6. For these cases we resorted to predictive mean matching with the mean of the 5 nearest neighbours (Carpenter and Kenward 2013). Following the imputa- 
Table 1. Generic overview of the Ml procedure with M replications of stochastic imputations of missing $T_{2}$ data in $y$. Subscripts refer to time (1 or 2) and sample unit $\left(1, \ldots n_{o b s}, \mathrm{n}_{\mathrm{obs}}\right.$ $+1, \ldots, n)$. Superscripts refer to the Ml replication $(1, \ldots, M)$. Imputed values are identified by a tilde $(\sim)$ and a mean by an overbar. Estimated variances are denoted by $\hat{V}$. Direct estimates based on $n_{o b s}$ sample units with $T_{2}$ data are in square brackets.

\begin{tabular}{|c|c|c|c|c|}
\hline$T_{1}$ & $T_{2}$ & $T_{2}^{(1)}$ & $\ldots$ & $T_{2}^{(M)}$ \\
\hline $\begin{array}{c}y_{1,1} \\
\vdots\end{array}$ & $\begin{array}{c}y_{2,1} \\
\vdots\end{array}$ & $\begin{array}{c}y_{2,1} \\
\vdots\end{array}$ & $\begin{array}{c}\cdots \\
\vdots\end{array}$ & $\begin{array}{c}y_{2,1} \\
\vdots\end{array}$ \\
\hline$y_{1, n_{o b s}}$ & $y_{2, n_{o b s}}$ & $y_{2, n_{o b s}}$ & $\ldots$ & $y_{2, n_{o b s}}$ \\
\hline$y_{1, n_{\text {obs }}+1}$ & miss & $\tilde{y}_{2, n_{\text {obs }}+1}^{(1)}$ & $\ldots$ & $\tilde{y}_{2, n_{\text {obs }}+1}^{(M)}$ \\
\hline$\vdots$ & $\vdots$ & $\vdots$ & $\vdots$ & $\vdots$ \\
\hline$y_{1, n}$ & miss & $\tilde{y}_{2, n}^{(1)}$ & $\cdots$ & $\tilde{y}_{2, n}^{(M)}$ \\
\hline $\bar{y}_{1}$ & {$\left[\bar{y}_{2}\right]$} & $\overline{\tilde{y}}_{2}^{(1)}$ & $\ldots$ & $\overline{\tilde{y}}_{2}^{(M)}$ \\
\hline$\hat{V}\left(\bar{y}_{1}\right)$ & {$\left[\hat{V}\left(\bar{y}_{2}\right)\right]$} & $\hat{V}\left(\overline{\tilde{y}}_{2}^{(1)}\right)$ & $\ldots$ & $\hat{V}\left(\overline{\tilde{y}}_{2}^{(M)}\right)$ \\
\hline
\end{tabular}

tions of cover-type area proportions, a post-calibration was done to ensure that the five proportions would add to 1.0. Year of interpretation for $T_{1}$ and $T_{2}$ data had no practically relevant influence on the results. A more complex MI approach with a multinomial logistic regression model was tried but we found no advantage in terms of implementation or estimates of precision.

Changes in area-proportions were estimated as the difference between estimates of $T_{2}$ and $T_{1}$ area proportions for each of the $M$ replications and $n$ sample units. Estimation of means and variances of these changes followed the principles laid out in [1].

$\mathrm{Ml}$ estimation of state and change in unit area stem volume In an NFI sample unit, the area in a given cover-type (CT) varies among plots $(j, j=1, \ldots, n)$ and there is a positive correlation between area and total stem volume $(t v o l)$. For that reason we employed ratio estimators (Cochran 1977) for per unit area stem volume (VOL). For a full complement of $n$ sample units the estimators of the mean VOL m ${ }^{3} \mathrm{ha}^{-1}$ at $T_{t}(t$ $=1,2)$ and the change $T_{2}-T_{1}$ in a cover-type were

[2] $V \hat{O} L_{C T, t}=\frac{\sum_{j=1}^{n} \operatorname{tvol}_{C T, t, j}}{\sum_{j=1}^{n} \operatorname{area}_{C T, t, j}}, \Delta V \hat{O} L_{C T, 2-1}=V \hat{O} L_{C T, 2}-V \hat{O} L_{C T, 1}$

with variance (Cochran 1977)

$$
\begin{gathered}
{[3] \hat{V}\left(V \hat{O} L_{C T, t}\right)=\frac{1}{n \bar{a}_{C T, t}^{2}}\left(\sum_{j=1}^{n} t v o l_{C T, t, j}^{2}-2 V \hat{O} L_{C T, t}\right.} \\
\left.\sum_{j=1}^{n} \operatorname{area}_{C T, t, j} t v o l_{C T, t, j}+V \hat{O} L_{C T, t}^{2} \sum_{j=1}^{n} \operatorname{area}_{C T, t, j}^{2}\right)
\end{gathered}
$$

Where $\bar{a}_{C T, t}$ is the mean of area $a_{C T, t, j}$. The variance of a change estimate was computed as:

$$
\begin{aligned}
\text { [4] } \hat{V}( & \left.\Delta V \hat{O} L_{C T, 2-1}\right)=\hat{V}\left(V \hat{O} L_{C T, 2}\right)+\hat{V}\left(V \hat{O} L_{C T, 1}\right) \\
& -2 C \hat{O} V\left(V \hat{O} L_{C T, 2}, V \hat{O} L_{C T, 1}\right)
\end{aligned}
$$

Where the last term on the right-hand-side is the covariance between the volume (ratio) at $T_{1}$ and $T_{2}$. We obtained a firstorder approximation to this covariance from an estimate of the temporal correlation of volume per ha estimates at time $T_{1}$ and $T_{2}$ and the squared root of the product of the two variances $V\left(V O \hat{O} L_{C T, t}\right), t=1,2$ of a volume ratio estimate. The alternative would be a jackknife estimator (Wolter 2007). The estimators in [3] and [4] make it clear that the MI procedure requires an imputation of both area $_{C T, 2, j}$ and $t v o l_{C T, 2, j}, j=n_{o b s}$ $+1, \ldots ., n$. Imputed values of area $a_{C T, 2, j}, j=n_{o b s}+1, \ldots ., n$ were obtained by multiplying the above imputed area proportions with the fixed and known area of a sample unit. Values of $t v o l_{C T, 2, j}, j=n_{o b s}+1, \ldots ., n$ were, with the exception of NA in QC6, imputed in a two-step process: in step one, a stochastic prediction of $V O L_{C T, 2}$ was derived from a zero-truncated regression with $V O L_{C T, 1}$ as the sole (significant) predictor; and in step two, the predicted volume per unit area was multiplied by the prediction area $_{C T, 2}$. These models explained between 51 and $72 \%$ of the variation in VOL at $T_{2}$ in the remeasured plots.

For NA in QC6, the first step was to predict the $T_{2}-T_{1}$ increment $\left(\delta_{t_{2}-t_{1}}\right)$ in per unit area volume $\tilde{\delta}_{t_{2}-t_{1}}\left(V O L_{C T_{1, j}, j}\right) \geq 0$; and in a second step equate $\mathrm{tvol}_{C T, 2, j}$ to the product of $\left(V O L_{C T, 1, j}+\widetilde{\delta}_{t_{2}-t_{1}}\left(V O L_{C T, 1, j}\right)\right) a \tilde{r} e a_{C T, 2, j}$. The volume increment $\widetilde{\delta}_{t_{2}-t_{1}}\left(V O L_{C T, 1, j}\right)$ was predicted from the $n_{\text {obs }}$ units with positive $T_{1}{ }^{2-t_{1}}$ and $T_{2}$ values of area and $t v o l$, and depended on both the initial per unit area volume, and the number of years $\left(\Delta_{t_{2}-t_{1}}\right)$ between the first and second photo-interpretation. To complete a QC6 NA imputation a separate imputation of $\Delta_{t-t_{1}}$ was needed due to the lack of a singular and fixed value for this variable. To this end we drew, for each of the $n-\left(n_{\text {obs }}+1\right)$ units without $T_{2}$ data, a random integer from a Poisson distribution with an intensity parameter expressed as a linear model with an intercept and $T_{1}$ fitted to the re-interpreted observations. Random draws were subsequently truncated to comply with both the observed range of $\Delta_{t_{2}-t_{1}}$ year and the maximum observed $T_{2}$ value. An imputed value of $\Delta_{t_{2}-t_{1}}$ was held fixed across the $M$ replications. Finally, we forced the regression through the origin to ensure a positive prediction of volume increment. The forcing increased the regression residual errors by approximately $10 \%$ and lowered the coefficient of determination by 0.02 .

We explored improvements of these regression models by including rates of plot-level stand-replacing disturbances from the National Terrestrial Ecosystem Monitoring System (NTEMS) (White et al. 2014, Hermosilla et al. 2015). However, regression models with these rates (discretized to 11 intervals and separated to fire and harvest) were not materially better at explaining change in volume than models without these rates. With a predominance of small fractions of a 400 ha NFI unit size disturbed by fire or harvest, this result was no surprise.

\section{Results}

QC6: A summary of $T_{2}$ and change $\left(T_{2}-T_{1}\right)$ estimates of cover type proportions and cubic metre stem volume per ha is given 
Table 2. Direct (DI) and MI-based (MI) estimates of mean and sampling error (s.e.) of time $T_{2}$ and $T_{2}-T_{1}$ change in cover type $\left[C T\right.$ area proportions $\left[P_{C T}\right]$ and stem volume per unit area $\left(V L_{C T} m^{3}\right.$ ha-1 $)$ in the QC6 study region. Sample size for DI is 662 and 1272 for $\mathrm{Ml}$.

\begin{tabular}{|c|c|c|c|c|c|c|c|c|}
\hline & $\begin{array}{c}T_{2} \\
(\mathrm{MI}) \\
\text { mean }\end{array}$ & $\begin{array}{c}T_{2} \\
\text { (MI) } \\
\text { s.e. }\end{array}$ & $\begin{array}{c}T_{2} \\
(\mathrm{DI}) \\
\text { mean }\end{array}$ & $\begin{array}{c}T_{2} \\
\text { (DI) } \\
\text { s.e. }\end{array}$ & $\begin{array}{c}T_{2}-T_{1} \\
(\mathrm{MI}) \\
\text { mean }\end{array}$ & $\begin{array}{c}T_{2}-T_{1} \\
(\mathrm{MI}) \\
\text { s.e. }\end{array}$ & $\begin{array}{c}T_{2}-T_{1} \\
\text { (DI) } \\
\text { mean }\end{array}$ & $\begin{array}{c}T_{2}-T_{1} \\
\text { (DI) } \\
\text { s.e. }\end{array}$ \\
\hline$P_{N A}$ & 0.22 & 0.01 & 0.20 & 0.01 & -0.04 & 0.01 & -0.04 & 0.01 \\
\hline$P_{N T}^{N A}$ & 0.09 & 0.00 & 0.08 & 0.01 & 0.03 & 0.01 & 0.01 & 0.01 \\
\hline$P_{T B}^{N T}$ & 0.13 & 0.01 & 0.15 & 0.01 & 0.03 & 0.01 & 0.02 & 0.01 \\
\hline$P_{T C}^{I D}$ & 0.37 & 0.01 & 0.33 & 0.02 & -0.01 & 0.01 & 0.04 & 0.01 \\
\hline$P_{T M}^{T}$ & 0.19 & 0.01 & 0.24 & 0.01 & -0.01 & 0.01 & -0.04 & 0.01 \\
\hline$P_{F O}^{1 N T}$ & 0.78 & 0.01 & 0.80 & 0.01 & 0.04 & 0.01 & 0.04 & 0.01 \\
\hline$V O L_{N A}$ & 1.3 & 0.1 & 0.4 & 0.3 & -4.1 & 0.4 & -5.1 & 0.6 \\
\hline$V O L_{T B}^{N A}$ & 145.0 & 4.4 & 150.4 & 4.8 & -1.5 & 3.2 & 7.8 & 2.7 \\
\hline$V O L_{T C}$ & 118.0 & 2.4 & 113.7 & 2.5 & 2.4 & 1.6 & 2.5 & 1.2 \\
\hline$V O L_{T M}^{I C}$ & 113.6 & 2.8 & 120.0 & 3.2 & -0.6 & 2.0 & 7.9 & 2.1 \\
\hline$V O L_{F O}$ & 107.5 & 1.9 & 111.1 & 2.8 & -5.0 & 1.8 & -2.7 & 2.5 \\
\hline
\end{tabular}

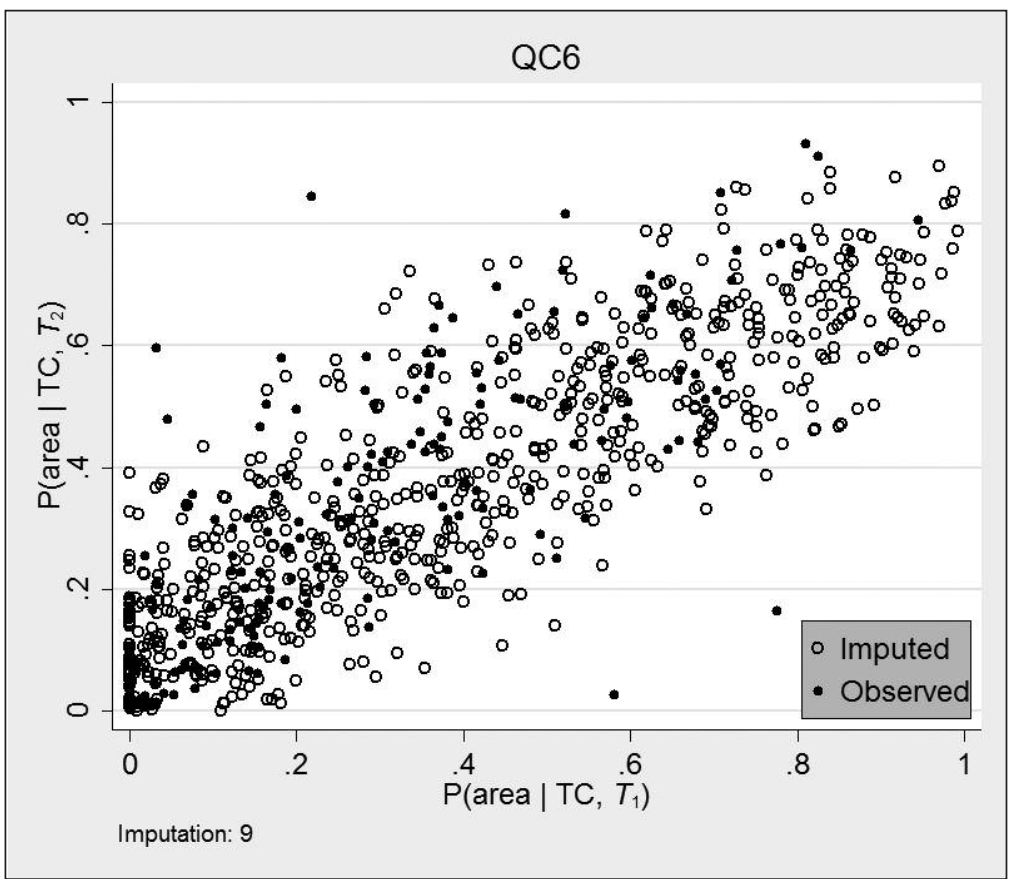

Fig. 4. Examples from study region QC6 of imputations of $T_{2}$ TC area proportions with a truncated regression model. Imputations are from a randomly selected replication (here 9). Note the scatter plot of observed area proportions is based on the 610 plots with both $T_{2}$ and $T_{1}$ interpretations.

in Table 2. For TC and TM proportions at $T_{2}$ the $\mathrm{MI}$ and direct (DI) estimates differed by $4-5 \%$. Large and significant $T_{1}$ differences between re-interpreted and non-re-interpreted plots in TB and TM proportions were the main contributor to these apparent differences. All remaining MI and DI area proportions were within $2 \%$ of each other. Given the estimates of error, this difference could arise by chance. MI-based estimates of errors were not lower than corresponding errors in the direct estimates, despite having a fairly strong temporal correlation of 0.4-0.8 (mean $=0.7)$ and a larger sample size. An example of imputations of $T_{2}$ TC area proportions in a randomly selected replication is in Fig. 4. There is a wide scat- ter in imputed $T_{2}$ proportions for a given $T_{1}$ proportion, but the overall pattern is comparable to the observed pattern in the 610 plots with a $T_{2}$ interpretation. The observed scatter is a mix of actual changes and spurious changes resulting from differences in photo-interpretation (Magnussen and Russo 2012).

MI and DI estimates of change in cover type area proportions were generally in agreement in terms of direction and magnitude considering the estimates of errors of approximately $1 \%$. Exceptions are TM and TC but given the large $T_{1}$ differences in areas, we do not consider these disagreements to be artefacts of MI. A large replication variance of area proportions (necessitating more than the usually recommended four to five MI replications) and differences in $T_{1}$ area proportions are the main explanation as to why the MI estimates of error do not suggest any reduction over the DI estimates despite a near doubling of the sample size used in the MIs.

Statistics from the compiled Landsat time series of stand-replacing harvest and fires in the study region (Hermosilla et al. 2015) suggest that plots with $T_{2}$ interpreted data experienced a higher rate of harvest and a lower rate of fires during the years 1994-2011 than represented by plots with only a $T_{1}$ interpretation. We could, however, not isolate an impact of these differences on the area proportions.

Time $T_{2}$ MI and DI estimates of VOL $\mathrm{m}^{3} \mathrm{ha}^{-1}$ do not suggest any important differences, at least when considering the associated estimates of error. Overall, the MI estimates have slightly lower (approximately 10\%) errors, but still far from the maximal possible reduction of $44 \%$.

A scatterplot in Fig. 5 gives an example of imputations in a randomly selected replication. An observation falling on the $x$-axis means that the per unit area stem volume of a covertype went to zero either due to a reclassification or a standreplacing disturbance. A point on the $y$-axis is also most likely 
due to a reclassification to a cover type that was not recognized at $T_{1}$. As in the case of area proportions, the pattern of imputed values was similar to the pattern in the actual data. We again emphasize that an observed change in volume may reflect not only actual changes but also subject- and methodspecific changes in interpretation and yield tables.

Estimates of change in volume per hectare for TB, TC, $\mathrm{TM}$, and FO estimated via MI and DI were distinctly different in case of TB and TM as anticipated from the $T_{2}$ results in terms of direction and magnitude. We attribute these dif-

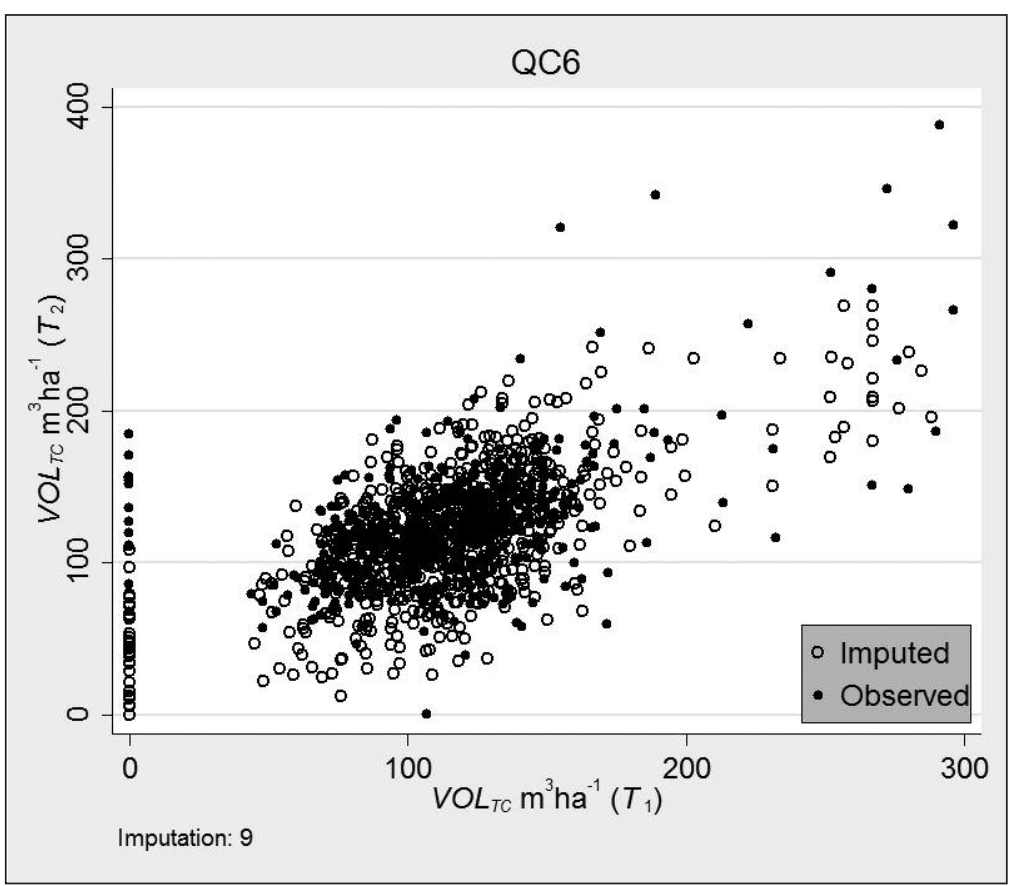

Fig. 5. Examples from study region QC6 of imputations of $T_{2}$ TC stem volume with a linear regression model. Imputations are from a randomly selected replication (here 9). Note the scatter plot of observed volumes is based on the 610 plots with both $T_{2}$ and $T_{1}$ interpretations. ferences to the aforementioned differences in $T_{1}$ area proportions. The relatively large estimates of errors associated with these change estimates calls for a cautionary interpretation. The MI estimates of errors of change were again not materially different from parallel DI estimates. There is a lack of additivity in the volume estimates in Table 2. This is, unfortunately, a characteristic of the ratio-estimators we used. Additivity could have been superimposed by the technique of iterative proportional fitting (Jirousek and Preucil 1995, Fuller 2009).

ON6: A summary of $T_{2}$ and change $\left(T_{2}-T_{1}\right)$ estimates of cover type proportions and cubic metre stem volume per ha is given in Table 3 . Cover type proportions at $T_{2}$ for TB, TC, and $\mathrm{TM}$, estimated via MI and DI, were within $0-4 \%$ of each other. The differences largely reflect differences in $T_{1}$ proportions between plots with or without a $T_{2}$ re-interpretation. As was the case in QC6, there is no apparent reduction in the MI estimates of error in area proportions that customary would be expected from the substantial increase in the number of plots used in MI. An example of imputations of $T_{2}$ TC area proportions in a randomly selected replication is given in Fig. 6. The scatterplot suggests that imputations were slightly closer to the one-to-one line (of no change) but also that the number of imputations with 'no-change' is slightly lower than in the actual data.

Apart from time $T_{2}$ estimates of VOL m ${ }^{3} \mathrm{ha}^{-1}$ in classes TB and TM, the MI and DI estimates were in close agreement. For TB and TM the differences were approximately $5 \%$ but related to differences in $T_{1}$ estimates. The MI estimates of standard errors were slightly lower (10\%) in $\mathrm{TB}, \mathrm{TM}$, and FO than the corresponding DI estimates. The scatterplot in Fig. 7 gives an example of volume imputations in a randomly selected replication. There is no apparent

Table 3. Direct (DI) and Ml-based (MI) estimates of mean and sampling error (s.e.) of time $T_{2}$ and $T_{2}-T_{1}$ change in cover type (CT) area proportions $\left(P_{C T}\right)$ and stem volume per unit area $\left(V O L_{C T} \mathrm{~m}^{3} \mathrm{ha}^{-1}\right.$ ) in the ON6 study region. Sample size for $\mathrm{DI}$ is 459 and 1210 for MI.

\begin{tabular}{|c|c|c|c|c|c|c|c|c|}
\hline & $\begin{array}{c}T_{2} \\
(\mathrm{MI}) \\
\text { mean }\end{array}$ & $\begin{array}{c}T_{2} \\
(\mathrm{MI}) \\
\text { s.e. }\end{array}$ & $\begin{array}{c}T_{2} \\
(\mathrm{DI}) \\
\text { mean }\end{array}$ & $\begin{array}{c}T_{2} \\
\text { (DI) } \\
\text { s.e. }\end{array}$ & $\begin{array}{c}T_{2}-T_{1} \\
\text { mean }\end{array}$ & $\begin{array}{c}T_{2}-T_{1} \\
(\mathrm{MI}) \\
\text { s.e. }\end{array}$ & $\begin{array}{c}T_{2}-T_{1} \\
(\mathrm{DI}) \\
\text { mean }\end{array}$ & $\begin{array}{c}T_{2}-T_{1} \\
\text { (DI) } \\
\text { s.e. }\end{array}$ \\
\hline$P_{N A}$ & 0.23 & 0.01 & 0.20 & 0.01 & -0.02 & 0.01 & -0.00 & 0.00 \\
\hline$P_{N T}^{N A}$ & 0.02 & 0.00 & 0.02 & 0.00 & -0.01 & 0.00 & -0.01 & 0.00 \\
\hline$P_{T B}^{N T}$ & 0.16 & 0.00 & 0.16 & 0.01 & 0.04 & 0.01 & 0.04 & 0.00 \\
\hline$P_{T C}^{I B}$ & 0.39 & 0.01 & 0.43 & 0.01 & -0.01 & 0.01 & -0.01 & 0.01 \\
\hline$P_{T M}^{I C}$ & 0.20 & 0.01 & 0.20 & 0.01 & -0.01 & 0.01 & -0.01 & 0.01 \\
\hline$P_{F O}$ & 0.77 & 0.01 & 0.80 & 0.01 & 0.02 & 0.00 & 0.00 & 0.00 \\
\hline$V O L_{N A}$ & 0.1 & 0.0 & 0.1 & 0.1 & -0.2 & 0.1 & -0.1 & 0.3 \\
\hline$V O L_{T B}^{N A}$ & 142.6 & 4.1 & 149.9 & 4.3 & -41.3 & 4.5 & -36.2 & 5.3 \\
\hline$V O L_{T C}$ & 115.4 & 2.2 & 113.0 & 2.2 & -11.4 & 2.6 & -11.3 & 3.1 \\
\hline$V O L_{T M}$ & 126.6 & 3.0 & 133.5 & 3.3 & -29.1 & 3.2 & -22.2 & 4.0 \\
\hline$V O L_{F O}$ & 121.1 & 1.8 & 122.3 & 2.2 & -18.3 & 2.2 & -15.5 & 2.9 \\
\hline
\end{tabular}




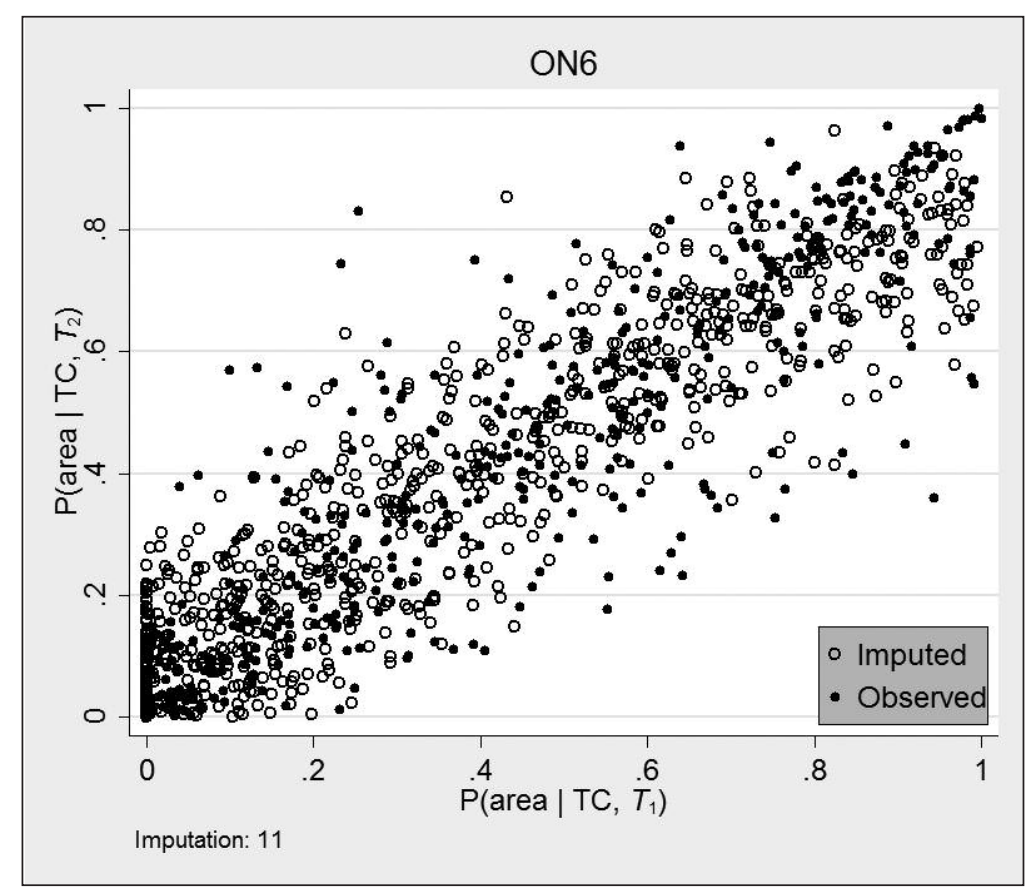

Fig. 6. Examples from study region ON6 of imputations of $T_{2} T C$ area proportions with a truncated regression model. Imputations are from a randomly selected replication (here 11). Note the scatter plot of observed area proportions is based on the 459 plots with both $T_{2}$ and $T_{1}$ interpretations.

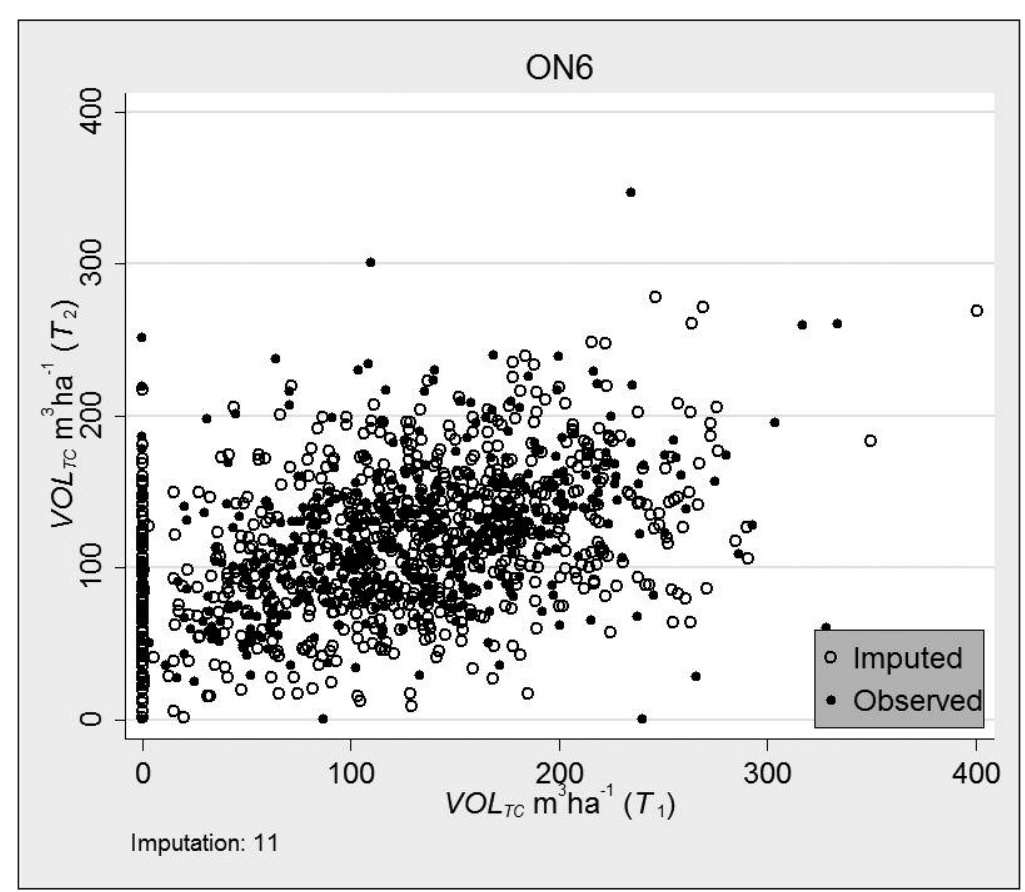

Fig. 7. Examples from study region ON6 of imputations of $T_{2} \mathrm{TC}$ stem volume with a linear regression model. Imputations are from a randomly selected replication (here 11). Note the scatter plot of observed volumes is based on the 459 plots with both $T_{2}$ and $T_{1}$ interpretations. important difference between the imputed and observed point scatter. Imputed and direct estimates of change in VOL m ${ }^{3} \mathrm{ha}^{-1}$ were similar in terms of direction and magnitude. Given relatively large standard errors on these change estimates, there is no reason to draw attention to specific differences. For the major covertypes in the forest category, the MI standard errors of a change in volume were approximately $30 \%$ lower than parallel DI estimates, still far from the maximum possible of $62 \%$.

SK9. A summary of $T_{2}$ and change $\left(T_{2}-T_{1}\right)$ estimates of cover type proportions and cubic metre stem volume per ha is given in Table 4 . Cover type proportions at $T_{2}$ for TB, TC, and $\mathrm{TM}$, estimated by MI and DI were within $0 \%-3 \%$ of each other, and judged by the estimates of error, they may well be due to chance. However, estimates of the proportion of area in NA differed by $5 \%$ which is mirrored in the derived proportions of FO. A comparison of $T_{1}$ area proportions in NA confirmed that the apparent difference between MI and DI should be seen as direct consequence of differences in the $T_{1}$ estimates. MI estimates of standard errors were generally lower than parallel DI estimates and close to a theoretical maximum reduction of $25 \%$. An example of imputations of $T_{2}$ TC area proportions in a randomly selected replication is provided in Fig. 8. There are some important differences in the pattern of observed and imputed $T_{2}$ proportions. There is a deficit of imputed proportions along the 1:1 line and a surplus of imputations in the $T_{1}$ range of 0.9 to 1.0 with a marked decrease in area. An observed pattern of a change from a proportion below 0.4 to a proportion above 0.8 was not apparent in the imputations. Similar issues were seen in other cover types and across replications.

MI and DI estimates of change in TB, TC, and TM cover type area proportions were basically identical. The same holds for associated estimates of error. The only important discrepancy is in the estimate of change of the NA land proportion and a concomitant change of the FO proportion. In light of the $T_{2}$ discrepancy in estimates of NA proportions, we should also expect estimates of change to diverge. Estimates of disturbance rates from NTEMS data (Hermosilla et al. 2015) suggested equal rates of fire and harvest in the two sets of plots during the period of observation. All differences in annualized rates were less than $0.03 \%$ (non-significant with bootstrap $t$-test).

Time $T_{2}$ MI and DI estimates of VOL m ${ }^{3} \mathrm{ha}^{-1}$ indicate a difference of approximately $5 \%$ in TB (Table 3); however, the estimates of errors suggest that this difference is likely due to chance. We do not see a consistent (across cover types) 
Table 4. Direct (DI) and MI-based (MI) estimates of mean and sampling error [s.e.) of time $T_{2}$ and $T_{2}-T_{1}$ change in cover type [CT area proportions $\left[P C T\right.$ ) and stem volume per unit area $\left(V O L_{C T} \mathrm{~m}^{3}\right.$ ha-1) in the SK9 study region. Sample size for $D I$ is 242 and 380 for Ml.

\begin{tabular}{|c|c|c|c|c|c|c|c|c|}
\hline & $\begin{array}{c}T_{2} \\
(\mathrm{MI}) \\
\text { mean }\end{array}$ & $\begin{array}{c}T_{2} \\
\text { (MI) } \\
\text { s.e. }\end{array}$ & $\begin{array}{c}T_{2} \\
(\mathrm{DI}) \\
\text { mean }\end{array}$ & $\begin{array}{c}T_{2} \\
(\mathrm{DI}) \\
\text { s.e. }\end{array}$ & $\begin{array}{c}T_{2}-T_{1} \\
(\mathrm{MI}) \\
\text { mean }\end{array}$ & $\begin{array}{c}T_{2}-T_{1} \\
(\mathrm{MI}) \\
\text { s.e. }\end{array}$ & $\begin{array}{c}T_{2}-T_{1} \\
\text { (DI) } \\
\text { mean }\end{array}$ & $\begin{array}{c}T_{2}-T_{1} \\
\text { (DI) } \\
\text { s.e. }\end{array}$ \\
\hline$P_{N A}$ & 0.41 & 0.02 & 0.46 & 0.03 & -0.04 & 0.01 & -0.02 & 0.01 \\
\hline$P_{N T}^{N A}$ & 0.02 & 0.00 & 0.02 & 0.01 & 0.02 & 0.00 & 0.01 & 0.01 \\
\hline$P_{T B}^{N I}$ & 0.15 & 0.01 & 0.15 & 0.01 & 0.00 & 0.01 & 0.01 & 0.01 \\
\hline$P_{T C}^{I D}$ & 0.34 & 0.02 & 0.31 & 0.02 & 0.00 & 0.01 & -0.00 & 0.01 \\
\hline$P_{T M}^{I C}$ & 0.07 & 0.02 & 0.06 & 0.01 & 0.01 & 0.02 & -0.00 & 0.01 \\
\hline$P_{F O}^{I M}$ & 0.59 & 0.02 & 0.54 & 0.03 & 0.04 & 0.01 & 0.02 & 0.01 \\
\hline$V O L_{N A}$ & 13.9 & 2.2 & 13.6 & 2.4 & 0.5 & 1.6 & -1.3 & 1.1 \\
\hline$V O L_{N T}^{N A}$ & 5.4 & 2.2 & 2.4 & 1.1 & 11.5 & 2.8 & 4.0 & 1.5 \\
\hline$V O L_{T B}^{N T}$ & 132.7 & 5.7 & 140.2 & 5.9 & -19.9 & 5.3 & -24.4 & 4.9 \\
\hline$V O L_{T C}^{1 B}$ & 69.3 & 3.5 & 66.7 & 3.1 & -14.3 & 5.4 & -14.1 & 3.6 \\
\hline$V O L_{T M}^{I C}$ & 126.8 & 10.3 & 129.1 & 11.0 & -32.0 & 9.2 & -30.4 & 11.1 \\
\hline$V O L_{F O}^{I M}$ & 90.0 & 3.8 & 91.8 & 4.4 & -4.7 & 3.2 & -21.3 & 4.3 \\
\hline
\end{tabular}

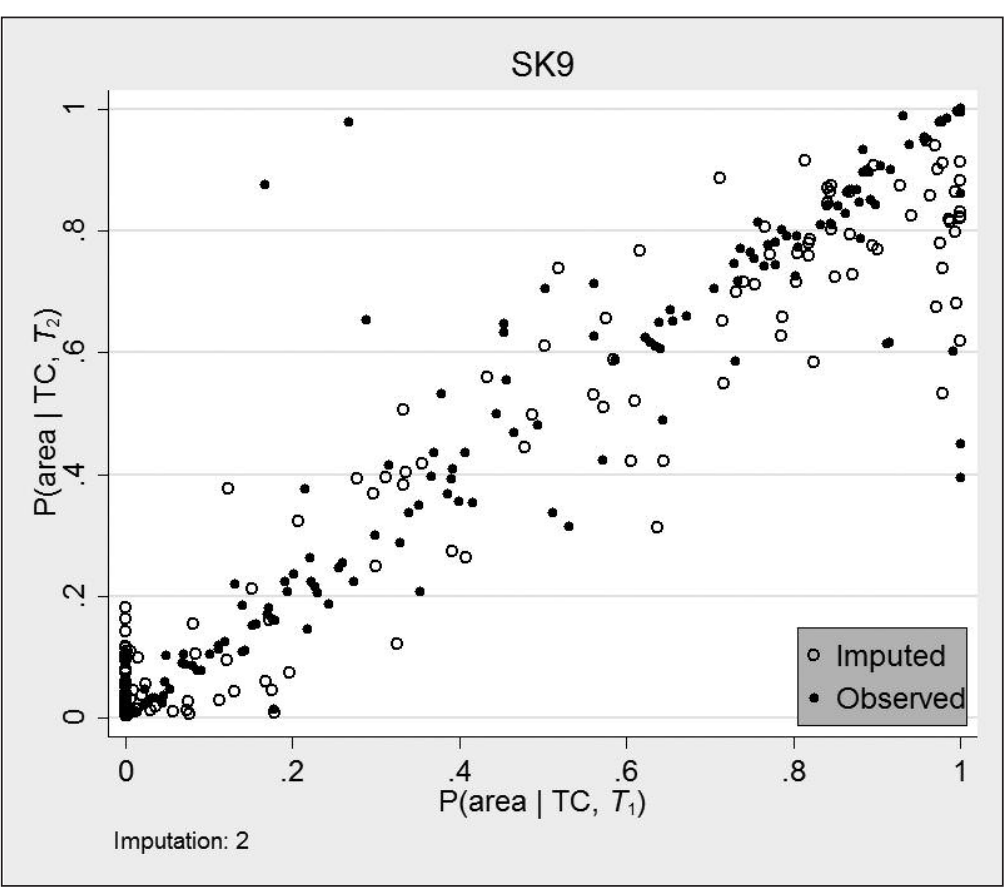

Fig. 8. Examples from study region SK9 of imputations of $T_{2} T C$ area proportions with a truncated regression model. Imputations are from a randomly selected replication (here 2). Note the scatter plot of observed area proportions is based on the 242 plots with both $T_{2}$ and $T_{1}$ interpretations.

reduction in $\mathrm{MI}$ errors from boosting the sample size from 242 to $380(57 \%)$, a reflection of cover-type specific differences in the strength of the temporal correlation of per unit area volume estimates. The scatterplot in Fig. 9 gives an example of volume imputations in a randomly selected replication. We again observe a deficit of imputations on the 1:1 line of no change in volume, but otherwise the two patterns of scatter appear to concur.

MI and DI estimates of change in unit area stem volume for TB, TC, and TM agreed to within an allowance for error.
A significant disagreement was seen in the NT estimate of change and consequently also in the FO estimate. We could not identify an explanation for this discrepancy. MI estimates of errors were in four cases larger than parallel DI errors and in two cases (TM and FO) smaller.

\section{Discussion}

Multiple imputations can be a powerful statistical procedure to reduce bias and improve precision of forest inventories with non-trivial issues of missing items and unit-level responses (McRoberts 2003, Patterson et al. 2012). Bias reduction and improvements in precision are contingent on the data being missing at random (MAR), conditional on the covariates and information used to generate an imputation (Scott 1984, Cunia and Kyaw 1985, Brown 1990, Tang et al. 2003). In our case studies, we have not been able to prove or disprove the correctness of the MAR assumption. If the models we have used are correct for units with- and without $T_{2}$ information, our MAR assumption would be satisfied. A retrospective assessment will be possible at a later time when data are obtained for units currently without $T_{2}$ data. It also appears that the combination of $T_{1}$ differences and relatively weak contemporaneous and temporal correlations in the data prevented us from achieving practically important improvement in precision. In forest inventories, the MI approach works best for undisturbed plots where the temporal correlation between the state at two points in time is generally strong for shorter periods (years) between observations, declining as the number of years between observations increases (Massey et al. 2014, McRoberts et al. 2016). In this regard, a stand-replacing disturbance event acts as a 'correlation-breaker'. Our scatterplots provided illustrative examples of this issue. Imputations could have been improved considerably with information 


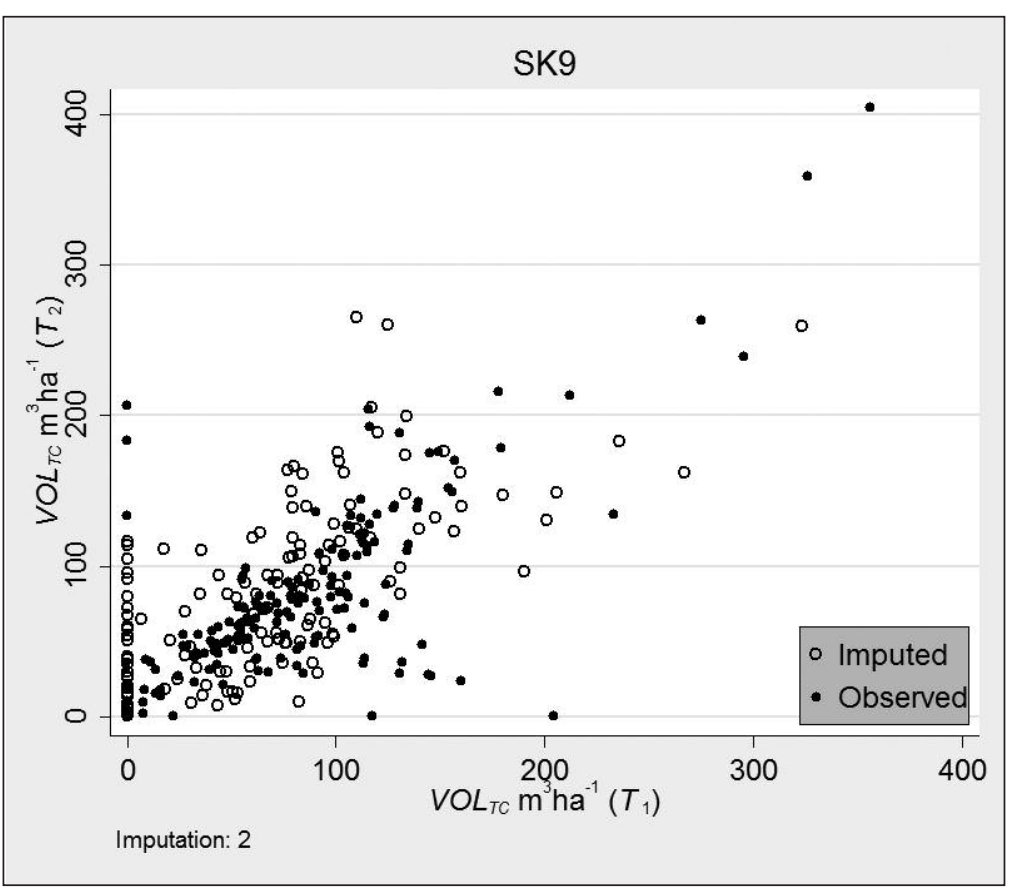

Fig. 9. Examples from study region SK9 of imputations of $T_{2}$ TC stem volume with a linear regression model. Imputations are from a randomly selected replication (here 2). Note the scatter plot of observed volumes is based on the 242 plots with both $T_{2}$ and $T_{1}$ interpretations.

from covariates on the presence/absence of disturbances. In an inventory based on 400 ha photo-interpreted plots, a second kind of 'correlation-breaker' appears in the form of interpreter-specific factors or through changes in the media or guidelines governing an interpretation (Holmström et al. 2001, Holmström 2002, Ståhl et al. 2011, Magnussen and Russo 2012).

The best strategy to minimize the impact of 'correlationbreakers' is to form strata of disturbed plots and use a logicmodel for the anticipated consequence of a stand-replacing disturbance (Reams and McCollum 2000, Massey et al. 2014). The Canadian NFI is actively in pursuit of this option but an operational system will not be in place for some years to come. Stand-replacing disturbance data from NTEMS (Hermosilla et al. 2015) would form a natural basis for identifying a stratum of disturbed land. The full use of this information requires a spatially explicit linkage to stand-polygons within the NFI data base system. Ideally we would have external (to NFI) models for updating data from disturbed stands that could be used in connection with mixed estimators of state and change (Dixon and Howitt 1979, Kangas 1991, Van Deusen 1996).

In our study, the inventory plots with missing $T_{2}$ information did not constitute a spatially random subsample of the $T_{1}$ plots. Despite a large degree of spatial overlap there were several compact sub-regions with missing $T_{2}$ data. However, the degree of overlap was such that it seems reasonable to assume that the identified models capturing the association between $T_{1}$ and $T_{2}$ attribute values holds irrespective of whether $T_{2}$ data is missing or not. When this assumption holds, our MI procedures preserve the effect of $T_{1}$ differences in the predictions for $T_{2}$. For the Canadian NFI with photo-interpreted data, the strongest impetus to use MI on a routine basis may therefore come from a general anticipation of $T_{1}$ differences between units with and without current information at time $T_{2}$. In this scenario, our MI estimators of state and change are likely less biased than estimators based exclusively on units having $T_{2}$ data. Addition of explicit spatial linkages to disturbance events should make MI even more attractive.

The duality of direct and MI $T_{2}$ estimates and estimates of change $\left(T_{2}-T_{1}\right)$ naturally raises the question of which set of estimates is more correct or 'believable.' Acceptance of unverified assumptions may meet with resistance. A compromise in the form of composite estimators (Gregoire and Walters 1988, Fuller 2009) may offer a more palatable alternative as it formulates a combination of the direct and MI estimators based on a weighting of the provided information in support of either.

For national forest inventories with a spatial balance in the number of plots measured in different years (Van Deusen 1997, McRoberts 2001), an important rationale for using MI is to boost the variance effective sample size and the associated improvement in precision. In a Canadian NFI context with photo-interpreted data, however, this generally attractive aspect of MI may not materialize to its full potential. An expectation of $T_{1}$ differences in area-proportions and per unit area stem-volume, predicates a relatively large Monte-Carlo error (Koehler et al. 2009), all else equal, which translates to a recommendation of a relatively large number of $\mathrm{MI}$ replications (20 in this study) and modest gains in precision. Far fewer replicates are needed for data with small $T_{1}$ differences and stronger temporal and contemporaneous correlations, (Kangas 1991, McRoberts 2003). A fully efficient fractional imputation (Fuller 2009) may be a theoretically attractive alternative to our MI, but computationally more demanding and lacks readily accessible software.

The large sampling units in the Canadian NFI with multiple cover-types and trees of different ages impose limitations on available MI options. The popular nearest neighbour technique (viz. 'hot deck'; Chen and Shao 2001, Kim and Fuller 2004, Carpenter and Kenward 2013) for multivariate imputations (McRoberts 2001, Eskelson et al. 2009a, 2009b) was considered but we failed to construct a meaningful definition of similarity (distance) due to the curse of dimensionality (Marimont and Shapiro 1979). Also, our pool of plots used as 'donors' for high-dimensional imputations was too small.

Although readily available software for MI and implementation may at first look straight-forward, it is not trivial and requires expertise in both forestry and statistics. The multivariate nature of forest inventories, restrictions of value ranges, and functional relationships among attributes of interests are challenges to consider.

Our MI approach was hierarchical but not multivariate: we began by imputing missing area proportions that were then used to complete imputations of volume. Multivariate (simultaneous) imputations would be an alternative (Carpenter and Kenward 2013). However, as opposed to tvol, we 
found no significant correlation between area proportions and per unit area stem volume. That and the fact that we employ ratio estimators for stem volume justify our univariate approach. Our presentation of MI results and discussion has centered on MI as a tool in support of inference. It is equally clear that one might consider imputed data as a replacement for missing values in a NFI data base (Eskelson et al. 2009b, Traub et al. 2017). However, this may generate bias in estimates of change over time when, with the privilege of hindsight, an imputation turns out to be an outlier.

\section{Acknowledgements}

The authors would like to thank all Canadian provincial and territorial government agencies who collaborated in the National Forest Inventory program and the individuals involved, both past and present. In particular, we thank Lane Gelhorn, Joe Kapron, and Antoine Leboeuf for their work on the NFI in Saskatchewan, Ontario, and Quebec, respectively.

\section{References}

Bokalo, M., S.J.Titus and D.P. Wiens. 1996. Sampling with partial replacement extended to include growth projections. For. Sci. 42 : 328-334.

Brown, C.H. 1990. Protecting against nonrandomly missing data in longitudinal studies. Biometrics.

Carpenter, J.R. and M.G. Kenward. 2013. Multiple imputation and its application. Wiley, $345 \mathrm{p}$.

Carroll, R.J., D. Ruppert and L.A. Stefanski. 1995. Measurement error in nonlinear models. Chapman \& Hall, London, 305 p.

Chen, J.H. and J. Shao. 2001. Jackknife variance estimation for nearest-neighbor imputation. J. Am. Stat. Assoc. 96 (453): 260-269. Cochran, W.G. 1977. Sampling techniques. Wiley, New York, 380 p. Corona, P., G. Chirici, S. Franceschi, D. Maffei, M. Marcheselli, C. Pisani et al. 2014. Design-based treatment of missing data in forest inventories using canopy heights from aerial laser scanning. Can. J. For. Res. 44 (8): 892-902.

Crookston, N.L. and A.O. Finley. 2008. yalmpute: An R Package for kNN Imputation. J. Stat. Softw. 23 (10): 16.

Cunia, T. and U.S. Kyaw. 1985. Sampling with partial replacement with different types of samples. Can. J. For. Res. 15: 191-194.

Dixon, B.L. and R.E. Howitt. 1979. Continuous Forest Inventory Using a Linear Filter. For. Sci. 25 (4): 675-689.

Domke, G.M., C.W. Woodall, B.F. Walters, R.E. McRoberts and M.A. Hatfield. 2014. Strategies to compensate for the effects of nonresponse on forest carbon baseline estimates from the national forest inventory of the United States. For. Ecol. Manage. 315: 112-120. 10.1016/j.foreco.2013.12.031

Eskelson, B.N.I., H. Temesgen and T.M. Barrett. 2009a. Estimating Current Forest Attributes from Paneled Inventory Data Using Plot-Level Imputation: A Study from the Pacific Northwest. For. Sci. 55 (1): 64-71.

Eskelson, B.N.I., H. Temesgen, V. Lemay, T.M. Barrett, N.L. Crookston and A.T. Hudak. 2009b. The roles of nearest neighbor methods in imputing missing data in forest inventory and monitoring databases. Scand. J. For. Res. 24 (3): 235-246.

Fuller, W.A. 1987. Measurement Error Models. Wiley, New York. Fuller, W.A. 2009. Sampling Statistics. Wiley, New York, 454 p. Gillis, M.D., A.Y. Omule and T. Brierley. 2005. Monitoring Canada's forests: The National Forest Inventory. For. Chron. 81 (2): 214-221.

Glynn, R.J., N.M. Laird and D.B. Rubin. 1993. Multiple imputation in mixture models for nonignorable nonresponse with follow-up. J. Am. Stat. Assoc. 88: 984-993.

Good, P. 1993. Permutation tests. Springer, New York, 226 p.
Greene, W.H. 2012. Econometric analysis. 7 edn. Prentice Hall, Upper Saddle River, NJ.

Gregoire, T.G. and D.K. Walters. 1988. Composite vector estimator by weighting inversely proportional to variance. Can. J. For. Res. 18: 282-284.

Haywood, A., A. Mellor and C. Stone. 2016. A strategic forest inventory for public land in Victoria, Australia. For. Ecol. Manage. 367: 86-96. http://dx.doi.org/10.1016/j.foreco.2016.02.026

Hermosilla, T., M.A. Wulder, J.C. White, N.C. Coops and G.W. Hobart. 2015. An integrated Landsat time series protocol for change detection and generation of annual gap-free surface reflectance composites. Remote. Sens. Environ. 158: 220-234.

Holmström, H. 2002. Estimation of single-tree characteristics using the $\mathrm{kNN}$ method and plotwise aerial photograph interpretations. For. Ecol. Manage. 167 (1-3): 303-314.

Holmström, H., M. Nilsson and G. Ståhl. 2001. Simultaneous estimations of forest parameters using aerial photograph interpreted data and the $\mathrm{k}$ nearest neighbour method. Scand. J. For. Res. 16 (1): 67-78.

Jirousek, R. and S. Preucil. 1995. On the effective implementation of the iterative proportional fitting procedure. Comp. Stat. Data Anal. 19 (2): 177-189.

Kangas, A. 1991. Updated measurement data as prior information in forest inventory. Silv. Fenn. 25 (3): 10.

Kim, J.K. and W. Fuller. 2004. Fractional hot deck imputation. Biometrika 91 (3): 559-578.

Koehler, E., E. Brown and J.-P.A. Haneuse. 2009. On the assessment of Monte Carlo error in simulation-based statistical analyses. Am. Stat. 63 (2): 155-162.

Little, R.J.A. and D.B. Rubin. 1987. Statistical analysis with missing data. Wiley.

MacDicken, K.G. 2015. Global forest resources assessment 2015: What, why and how? For. Ecol. Manage. 352: 3-8.

Magnussen, S. and G. Russo. 2012. Uncertainty in photo-interpreted forest inventory variables and effects on estimates of error in Canada's National Forest Inventory. Forest. Chron. 88 (4): 439-447. Marimont, R.B. and M.B. Shapiro. 1979. Nearest Neighbour Searches and the Curse of Dimensionality. IMA J. Appl. Math. 24 (1): 59-70.

Massey, A., D. Mandallaz and A. Lanz. 2014. Integrating remote sensing and past inventory data under the new annual design of the Swiss National Forest Inventory using three-phase design-based regression estimation. Can. J. For. Res. 44: 1177-1186.

Matis, K.G., J.C. Hetherington and J.Y. Kassab. 1984. Sampling with partial replacement - A literature review. Comm. For. Rev. 63: 193-206.

McRoberts, R.E. 2001. Imputation and model-based updating techniques for annual forest inventories. For. Sci. 47 (3): 322-330.

McRoberts, R.E. 2003. Compensating for missing plot observations in forest inventory estimation. Can. J. For. Res. 33 (10): 1990-1997. McRoberts, R.E., E. Næsset and T. Gobakken. 2016. The effects of temporal differences between map and ground data on map-assisted estimates of forest area and biomass. Ann. For. Sci. 73 (4): 839-847. Miller, R.G.J. 1981. Simultaneous Statistical Inference. 2 edn. Springer, New York, 293 p.

Patterson, P.L., J.W. Coulston, F.A. Roesch, J.A. Westfall and A.D. Hill. 2012. A primer for nonresponse in the US forest inventory and analysis program. Environ. Monit. Assess. 184 (3): 1423-1433.

Pelz, D.R. and T. Cunia. 1985. National Forest Inventories in Europe. Univ. of Freiburg, Freiburg, Germany.

Reams, G.A. and P.C. Van Deusen. 1999. The southern annual forest inventory system. J. Agric. Biol. Environ. Stat. 4 (4): 346-360.

Reams, G.A. and J.M. McCollum. 2000. The use of multiple imputation in the southern annual forest inventory system. Gen. Tech. Rep, No. NC-122, US Forest Service, Moscow ID.

Rubin, D.B. 1987. Multiple imputation for nonresponse in surveys. Wiley, New York, 261 p. 
Scott, C.T. 1984. A new look at sampling with partial replacement. For. Sci. 30: 157-166.

Ståhl, G., A. Allard, P.A. Esseen, A. Glimskär, A. Ringvall, J. Svensson et al. 2011. National Inventory of Landscapes in Sweden (NILS)-scope, design, and experiences from establishing a multiscale biodiversity monitoring system. Env. Monit. Assess. 173 (1-4): 579-595.

StataCorp. 2016. Stata Statistical Software: Release 14.2. StataCorp LP, College Station, Texas.

Stinson, G., S. Magnussen, P. Boudewyn, F. Eichel, G. Russo, M. Cranny et al. 2016. Canada. In: National Forest Inventories: Assessment of Wood Availability and Use. C. Vidal, I.A. Alberdi, L.H. Mateo and J.J. Redmond (eds). Springer, Cham, CH., pp. 233-248.

Tang, G., R.J.A. Little and T.E. Raghunathan. 2003. Analysis of multivariate missing data with nonignorable nonresponse. Biometrika 90 (4): 747-764.

Tomppo, E. 2006. The Finnish National Forest Inventory. In: Forest Inventory: Methodology and Applications. A. Kangas and M. Maltamo (eds). Springer, Dordrecht, pp. 179-194.
Traub, B., R. Meile, S. Speich and E. Rösler. 2017. The data storage and analysis system of the Swiss National Forest Inventory. Computers and Electronics in Agriculture 132: 97-107.

Van Deusen, P.C. 1996. Incorporating predictions into an annual forest inventory. Can. J. For. Res. 26: 1709-1713.

Van Deusen, P.C. 1997. Annual forest inventory statistical concepts with emphasis on multiple imputations. Can. J. For. Res. 27: 379-384. White, J.C., M.A. Wulder, G.W. Hobart, J.E. Luther, T. Hermosilla, P. Griffiths et al. 2014. Pixel-based image compositing for large-area dense time series applications and science. Can. J. Rem. Sens. 40 (3). DOI: 10.1080/07038992.2014.945827.

Wolter, K.M. 2007. Introduction to variance estimation. 2nd edn. Springer, New York, 447 p.

Wulder, M.A. and T. Nelson. 2003. EOSD land cover classification legend report., Victoria British Columbia, pp. 1-81.

Wulder, M.A., J.C. White, M. Cranny, R.J. Hall, J.E. Luther, A. Beaudoin et al. 2008. Monitoring Canada's Forests. Part 1: Completion of the EOSD Land Cover Project. Can. J. Rem. Sens. 34 (6): 549-562. 